\title{
Simulation of the de plasma in carbon nanotube growth
}

David Hash ${ }^{\text {a) }}$, Deepak Bose ${ }^{\text {b) }}$, T. R. Govindan, and M. Meyyappan

NASA Ames Research Center, Moffett Field, CA 94035

\begin{abstract}
A model for the dc plasma used in carbon nanotube growth is presented, and onedimensional simulations of an acetylene/ammonia/argon system are performed. The effect of dc bias is illustrated by examining electron temperature, electron and ion densities, and neutral densities. Introducing a tungsten filament in the dc plasma, as in hot filament chemical vapor deposition with plasma assistance, shows negligible influence on the system characteristics.
\end{abstract}

PACS: 81.07.De, 81.15.Gh, 52.65.Kj

a) David.B.Hash@nasa.gov

b) also at Eloret Corporation 


\section{INTRODUCTION}

Carbon nanotubes (CNTs) have been receiving much attention for their potential in field emitter devices, displays, sensors, electrodes and other related applications. Growth on patterned substrates for these applications is facilitated by chemical vapor deposition (CVD). Recently, plasma enhanced CVD (PECVD) has been investigated by several groups and found to yield well-aligned multiwalled carbon nanotubes (MWNTs) and multiwalled carbon nanofibers (MWNFs) ${ }^{1-28}$ Whereas the MWNTs grown by PECVD appear like nanotube towers, the MWNFs are individual, freestanding structures, but are more defective with occasional bamboo-like or stacked cone inner core. ${ }^{23,29}$ A variety of plasma sources such as microwave, ${ }^{5-12}$ inductive, ${ }^{23-25} \mathrm{rf}$ capacitive, ${ }^{17}$ and $\mathrm{dc}$ sources $^{13-16,18-20}$ have been used to create a glow discharge of the feedgas mixture. A common substrate heating method is through a resistive heater. The use of hot filament in CVD, popular in diamond deposition, is also found in the CNT literature; ${ }^{1,2,4}$ but, a dc plasma through a pair of electrodes is normally added to take advantage of the electric field effect on alignment. Therefore, this approach is called dc plasma enhanced hot filament CVD (dc-HFCVD) or hot filament PECVD (HF-PECVD).

With wide ranging applications for CNTs, techniques that allow controlled growth on patterned substrates as well as those for large scale production to meet possible future commodity market needs (for structural composites) will assume increased importance. While early reports focused on growth recipes and application potential, it is important now to develop an understanding of the growth processes in order to realize commercial applications. In this regard, modeling and simulation of the process is a valuable tool. For example, a volume-averaged model of an inductive plasma of methane and hydrogen 
revealed ${ }^{30}$ the extent of methane dissociation $(95 \%)$ and the creation of higher order saturated hydrocarbons, such as $\mathrm{C}_{2} \mathrm{H}_{2}, \mathrm{C}_{2} \mathrm{H}_{4}, \mathrm{C}_{2} \mathrm{H}_{6}$ etc., among several radicals and ions. A kinetic model coupled with a two-dimensional reactive flow simulation analyzed ${ }^{31,32}$ the high pressure carbon monoxide (HiPCo) process for the bulk production of singlewalled nanotubes and correlated process variables to the growth rate.

In the present work, a dc plasma used in MWNT/MWNF growth is modeled and results from one-dimensional simulations are provided. The effects of dc bias as well as a tungsten filament on plasma and neutral properties are discussed. Since dc plasma sources are widely used now for CNT growth, the present exercise provides useful insight into the process mechanisms.

\section{MODEL}

The governing equations used to model the dc plasma reactor are as follows:

$$
\begin{aligned}
& \frac{\partial \rho_{s}}{\partial t}+\nabla \cdot \boldsymbol{J}_{s}=W_{s}+W_{s, f}+\frac{\rho_{s, i}-\rho_{s}}{\tau} \\
& \frac{\partial}{\partial t}\left(\rho_{n} C_{v, n} T\right)+\nabla \cdot \sum_{n}\left(h_{s} \boldsymbol{J}_{s}-\kappa_{s} \cdot \nabla T\right)=Q_{c}+Q_{C E}+Q_{f}-\sum_{n} \sum_{r} W_{s, r} \Delta H_{r}^{\circ} \\
& \frac{\partial}{\partial t}\left(\rho_{e} C_{v, e} T_{e}\right)+\nabla \cdot\left(h_{e} \boldsymbol{J}_{e}-\kappa_{e} \cdot \nabla T_{e}\right)=q_{e} \boldsymbol{J}_{e} \cdot \boldsymbol{E}-Q_{c}-\sum_{r} W_{e, r} \Delta H_{r}^{\circ} \\
& \nabla^{2} \Psi=-\frac{\rho_{c}}{\varepsilon_{0}} \\
& \boldsymbol{J}_{s}=\rho_{s} \mu_{s} \boldsymbol{E}-\frac{P \mathrm{D}_{s} M_{s}}{R_{g} T_{s}} \nabla \frac{P_{s}}{P}
\end{aligned}
$$


Equation (1) is a continuity equation written for electrons and each of the neutral and ionic species. $\rho$ is the mass density of the species; subscript $s$ stands for species number, and $t$ is time. $W_{s}$ is the source term representing the production/consumption of species through reactions. $W_{s, f}$ is a similar term for reactivity at the filament surface, though $\mathrm{H}_{2}$ dissociation is the only reaction considered on the filament. The last term on the righthand side of Eq. (1) is a one-dimensional representation of species loss due to flow through the exit where subscript $i$ denotes inlet and $\tau$ is a residence time. $J_{s}$ is the species flux described by Eq. (5) and consists of a drift and a diffusion term. $E$ is the electric field causing the drift (of electrons or ions); $\mu_{s}$ is the mobility (of electrons and ions); $\mathrm{D}_{\mathrm{s}}$ is the diffusivity of species $\mathrm{s}$ in the mixture; $M_{s}$ is molecular weight of species $s ; P$ is the system pressure; $P_{s}$ is the partial pressure of species $s$; and $R_{g}$ is the gas constant.

Note that the plasma is not in a thermodynamic equilibrium and therefore, individual temperatures for electrons, ions and neutrals need to be used in the analysis. The ions are heavy and exchange energy efficiently with the gas, and their temperature is taken to be constant at $0.1 \mathrm{eV}$. Therefore, energy equations are solved only for the neutral gas [Eq. (2)] and the electrons [Eq. (3)]. $T$ and $T_{e}$ are the gas and electron temperatures respectively. $T_{e}$ here simply represents $2 / 3$ of electron mean energy and its use does not imply the assumption of a Maxwellian distribution. $C_{v}$ is the specific heat; the subscript $n$ denotes neutral species; $h$ is the enthalpy; $\kappa$ is the thermal conductivity; and $\Delta H_{r}{ }^{\circ}$ is the heat of reaction for reaction $r$. The terms on the left side of the energy equations account for convective and conductive transport of energy. The neutrals gain energy through elastic collisions with electrons $\left(Q_{c}\right)$, charge exchange collisions with ions $\left(Q_{C E}\right)$ and from the filament $\left(Q_{f}\right)$. The electrons gain energy from the electric field through Joule 
heating $\left(q_{e} \boldsymbol{J}_{e} \cdot \boldsymbol{E}\right)$ and lose energy through elastic collisions with neutrals. $q_{e}$ in the Joule heating term represents the charge per mass of electrons, $-e / m_{e}$. In both Eqs. (2) and (3), the last term represents the heat of reaction from various inelastic collisions.

The plasma is essentially quasi-neutral in the center of the discharge but there is a significant charge separation in the sheaths. Poisson's equation [Eq. (4)] relates the charge and potential distribution throughout the plasma. $\Psi$ is the potential, $\varepsilon_{0}$ is the permittivity of free space, and $\rho_{c}$ is the charge density.

Because of earlier interest in using HFCVD systems for the deposition of diamond films, beginning in the late eighties, different means of incorporating the effects of the filament into a gas model were developed. ${ }^{33-46}$ The filament has two main effects in the HFCVD system: (1) the conduction of heat to the gas and (2) the catalytic dissociation of $\mathrm{H}_{2}$ on the filament surface. Much of the filament modeling ${ }^{33-41}$ involved assuming an experimentally measured filament temperature and either chemical equilibrium or nearequilibrium conditions with a specified incubation time at the filament given its high temperature. The earliest works ${ }^{33-37}$ did not account for the catalytic activity of the filament, but later research ${ }^{38-41}$ then included filament catalysis either by assuming the degree of dissociation of $\mathrm{H}_{2}$ to be given by the equilibrium or near-equilibrium dissociation fraction at the filament temperature and reactor pressure or by altering the incubation time to match experimental data. Further work $^{42-46}$ moved beyond the chemical equilibrium assumption and developed expressions for the rate of catalytic dissociation of $\mathrm{H}_{2}$ on the filament but continued to specify a filament temperature from experimental measurements. In the present work, the filament is treated as a point 
source/sink in the neutral energy and $\mathrm{H}_{2}$ and $\mathrm{H}$ density equations. A separate filament energy balance equation, in contrast to the previous research, is fully-coupled to the gas equations and solved for the filament temperature:

$$
\frac{I^{2} R}{A^{2}}=h\left(T_{f}-T\right) \frac{C}{A}+\varepsilon \sigma\left(T_{f}^{4}-T_{w}^{4}\right) \frac{C}{A}+Z \sqrt{P_{H_{2}}} \exp \left(-\frac{25380}{T_{f}}\right) \frac{\Delta H_{r}^{o}}{M_{H_{2}}} \frac{C}{A}
$$

The power produced by passing a current through the filament is dissipated by conduction to the gas, radiation to the walls and heat loss by $\mathrm{H}_{2}$ dissociation on the filament surface, as given by the three terms on the right-hand side of Eq. (6), respectively. $I$ is the filament current; $R$ is the filament resistivity; $A$ is the cross sectional area of the filament; $C$ is circumference of the filament; $\sigma$ is the Stefan-Boltzmann constant $\left(5.6705 \times 10^{-8} \mathrm{~W} \mathrm{~m}^{-2} \mathrm{~K}^{-4}\right) ; \varepsilon$ is the emissivity of the filament; $T_{w}$ is the wall temperature; $Z$ is the rate constant for $\mathrm{H}_{2}$ dissociation on the filament surface; $P_{H_{2}}$ is partial pressure of $\mathrm{H}_{2}$; and $M_{\mathrm{H}_{2}}$ is the molecular weight of $\mathrm{H}_{2}$.

Two separate conditions are considered for the filament: one in which the filament is clean and the second in which the filament is carburized. The resistivity of a clean filament as a function of temperature is taken to be: ${ }^{47}$

$$
R=-2.3936+0.025 T_{f}+2.476 \times 10^{-6} T_{f}^{2}-9.996 \times 10^{-11} T_{f}^{3}, \mu \Omega \cdot \mathrm{cm}
$$

and the tungsten emissivity ${ }^{48}$ is given by $\varepsilon=0.12\left(T_{f} / 1000\right)$. Carburization is the process by which carbon species adsorb to the surface of the filament and are incorporated into its structure. The effect of this process is to increase the resistivity and emissivity of the filament and also poison the catalytic decomposition of $\mathrm{H}_{2}$ at the surface. Zeiler et al. ${ }^{49}$ show that within one hour their tungsten filaments were completely carburized to form $\mathrm{W}_{2} \mathrm{C}$ in a gas mixture of $1 \% \mathrm{CH}_{4}$ and $99 \% \mathrm{H}_{2}$ at a pressure of 22.5 Torr. Given that $\mathrm{C}_{2} \mathrm{H}_{2}$ 
carburizes tungsten more readily than methane, ${ }^{50}$ it is likely that filaments under our conditions will be carburized even more quickly. To model a carburized filament, the resistivity ${ }^{51}$ of $\mathrm{W}_{2} \mathrm{C}$ is used:

$R=80\left[1+2.586 \times 10^{-4}\left(T_{f}-298\right)\right], \mu \Omega \cdot \mathrm{cm}$

along with the $\mathrm{W}_{2} \mathrm{C}$ emissivity ${ }^{52}$ given by $\varepsilon=0.185\left(T_{f} / 1000\right)$. The effect of poisoning the filament is modeled by reducing the dissociation rate by a constant.

The first term on the right-hand side of Eq. (6) represents the heat conduction to the gas and is equal to the $Q_{f}$ term in Eq. (2) which will only have a value at the filament location. Here, the heat transfer coefficient $h$ depends on Reynolds number $\mathrm{Re}^{53}$ through:

$$
h=\kappa_{g} / D\left(0.43+0.48 \sqrt{\operatorname{Re}_{D}}\right), W / m^{2} \cdot K
$$

where $\kappa_{g}$ is the thermal conductivity of the gas and $D$ is the diameter of the filament. The last term in Eq. (6) represents the energy dissipated in atomization of $\mathrm{H}_{2}$ on the surface of the tungsten filament. The rate expression for this process in pure $\mathrm{H}_{2}$ was first investigated by Langmuir in the earlier 1900 s and more recently validated. ${ }^{54}$ This expression would result in the following for $W_{H_{2} f}$ in Eq. (1):

$$
W_{H_{2}, f}=Z \sqrt{P_{H_{2}}} \exp \left(-\frac{25380}{T_{f}}\right) \frac{C}{A}
$$

with $W_{H, f}=-W_{H_{z} f}$. As with $Q_{f}$, these terms are zero away from the filament location.

The boundary conditions at the anode and cathode are as follows. Potential and gas temperature are specified at the electrodes. At the cathode, the electron temperature is set to $0.5 \mathrm{eV}^{55,56}$ and at the anode a diffusion cooling boundary condition ${ }^{57}$ is applied, $\nabla h_{e}=e \nabla \Psi$. Ions densities are extrapolated, and electron densities are determined by 
assuming a zero density at the anode and a secondary electron emission coefficient at the cathode of 0.05 . The neutral densities at the boundaries are determined by setting the mass flux to zero.

The governing equations were solved using a code called SEMS (semiconductor equipment modeling software). This is a multi-dimensional, multispecies, multitemperature, chemically reacting flow code ${ }^{58,59}$ The governing equations are discretized using an implicit finite difference scheme. The resulting difference equations are solved using a Gauss-Seidel line relaxation method. The code was first validated by running a few dc argon simulations for which results are available in the literature. ${ }^{60}$ Then, both dc and dc-HFCVD cases here were simulated in one-dimension (axial direction perpendicular to the electrodes). Two-dimensional effects are more important to establish uniformity issues over large wafers. Given that now the research is academic and most growth experiments are done on 1-2 cm pieces of wafers, 1D simulations are adequate initially to understand the plasma characteristics, which is the primary purpose here.

An acetylene/ammonia feedgas system is studied here as it appears to be the most popular among the users of dc plasma and dc-HFCVD reactors. 18 neutral species $\left(\mathrm{Ar}, \mathrm{Ar}^{+}, \mathrm{H}_{2}\right.$, $\mathrm{H}, \mathrm{C}_{2} \mathrm{H}_{4}, \mathrm{C}_{2} \mathrm{H}_{3}, \mathrm{C}_{2} \mathrm{H}_{2}, \mathrm{C}_{2} \mathrm{H}, \mathrm{C}_{2}, \mathrm{~N}_{2} \mathrm{H}_{4}, \mathrm{~N}_{2} \mathrm{H}_{3}, \mathrm{~N}_{2} \mathrm{H}_{2}, \mathrm{~N}_{2} \mathrm{H}, \mathrm{N}_{2}, \mathrm{NH}_{3}, \mathrm{NH}_{2}, \mathrm{NH}$ and $\mathrm{N}$ ), five charged species $\left(\mathrm{Ar}^{+}, \mathrm{NH}_{3}{ }^{+}, \mathrm{NH}_{4}{ }^{+}, \mathrm{C}_{2} \mathrm{H}_{2}{ }^{+}, \mathrm{C}_{2} \mathrm{H}_{3}{ }^{+}\right.$) and electrons are considered. A set of 140 reactions is included in the modeling. ${ }^{61}$ These consist of electron impact reactions (dissociation, ionization, dissociative ionization), charge exchange reactions, neutral reactions, and electron-ion recombination. Though the system can have conceivably more 
species and reactions, the present set was derived after eliminating species of relatively negligible concentrations and very slow reactions. No surface reactions on catalyst particles leading to the actual growth are considered. These reactions and mechanisms are unknown. Nevertheless, the current exercise considering only the plasma phase is still valuable, given that the actual growth on a $1-2 \mathrm{~cm}$ piece of a wafer for 10 minutes only provides a very small sink for the active species. Therefore, the computed densities for most purposes are within the accuracy limits of the various reaction rate constants and collision cross sections and should help to develop an understanding of the plasma process.

The grounded anode and the biased cathode are separated by $1.5 \mathrm{~cm}$. The substrate is normally placed on the cathode to receive the advantage of the large cathodic electric field. A $0.25 \mathrm{~mm}$ diameter tungsten filament is positioned $1 \mathrm{~cm}$ above the cathode for the dc-HFCVD simulations. The substrate temperature is taken to be independently controlled by a combination of a resistive heater and water cooling system. The substrate temperature is taken to be $700^{\circ} \mathrm{C}$ in all simulations. Other base conditions are as follows: pressure of 8 Torr, wall temperature of $450^{\circ} \mathrm{C}$, and flow rates of $100 \mathrm{sccm}$ of argon, $50 \mathrm{sccm}$ of $\mathrm{NH}_{3}$, and $25 \mathrm{sccm}$ of $\mathrm{C}_{2} \mathrm{H}_{2}$. The dc bias on the cathode is varied between 325 and $750 \mathrm{~V}$. The filament current is varied from $0 \mathrm{~A}$ (corresponding to pure de discharge only) to 15 A using both clean and carburized conditions. 


\section{RESULTS AND DISCUSSION}

\section{A. DC Discharge}

We discuss the results for pure de discharges first. In all the figures, the cathode sits at the zero point axial location on the left of the plots, and the anode is located on the right at $1.5 \mathrm{~cm}$. Figure 1 provides the relative abundance of various neutral species across the electrode gap with no filament and a dc bias at the cathode of $-325 \mathrm{~V}$. As expected, Ar is the most abundant since its inlet mole fraction is 0.571 and it is an inert species. The concentration of the other two input gases $\mathrm{C}_{2} \mathrm{H}_{2}$ and $\mathrm{NH}_{3}$ are approximately $7.4 \times 10^{15}$ and $4.3 \times 10^{13} \mathrm{~cm}^{-3}$ (volume-averaged) at the cathode compared to the input of $3.4 \times 10^{16}$ and $1.7 \times 10^{16} \mathrm{~cm}^{-3}$ thus representing $78 \%$ and $99.7 \%$ dissociation, respectively. $\mathrm{H}_{2}$ is produced in abundance through atomic hydrogen abstraction and recombination. Atomic hydrogen itself is produced from a variety of $\mathrm{C}_{2} \mathrm{H}_{2}$ and $\mathrm{NH}_{3}$ dissociation reactions. A stable hydrocarbon such as $\mathrm{C}_{2} \mathrm{H}_{4}$ is generated in the plasma and exhibits a density of $\sim 2 \times 10^{12} \mathrm{~cm}^{-3}$. It is interesting to note the complete dissociation of $\mathrm{NH}_{3}$ even at this relatively low bias of $-325 \mathrm{~V}$ (low for a dc discharge). Han et al. ${ }^{62}$ indicate that if $\mathrm{NH}_{3}$ is replaced with $\mathrm{N}_{2}$, only carbon films result; pure $\mathrm{C}_{2} \mathrm{H}_{2}$ without ammonia also did not provide any nanotubes. They speculated that the $\mathrm{H}$ supplied by $\mathrm{NH}_{3}$ dissociation provides additional etching effects, thus enhancing the formation of nanotubes. Chhowalla et al. ${ }^{19}$ also emphasize the etching effect of $\mathrm{NH}_{3}$ as an important factor in growing vertically oriented nanofibers.

The effect of dc bias on electron temperature is shown in Fig. 2(a). The electron temperature at the edge of the cathode sheath is very high due to the energy gained from 
the sheath electric field. The corresponding electric field profiles are also shown in Fig. 2(b). As the dc bias increases, the sheath field increases which leads to higher peaks for electron temperature. The high electron temperature will lead to high ionization rates and since ionization is endothermic, electrons lose energy following ionization. The drop in electron temperature, after the sheath and in the bulk, is due to this energy loss and heat conduction. The electron energy rises again in the anodic sheath due to local electric field. All this behavior is well known in the dc discharge literature. ${ }^{57,60}$ The electron temperature in the bulk is about $1-1.5 \mathrm{eV}$ depending on the bias. This compares with a Langmuir probe measurement of $1.5 \mathrm{eV}$ reported in Ref. 19. The higher electric fields in the sheath [Fig. 2(b)] with increased dc bias are responsible for the better alignment of MWNFs as observed in Ref. 16 and 19.

The effect of bias on ion and neutral densities is displayed in Fig. 3. The ion densities at the electrodes are the lowest since they recombine at the walls. The peaks seen outside the cathodic sheath $(\mathrm{x}=0.1-0.15 \mathrm{~cm})$ are due to the high electron temperature and density locally. In general, the shape of the ion density profile is dictated by the local balance among competing processes: production by ionization, loss by recombination in the bulk, wall loss and smoothing out by diffusion. Figure 3(a) illustrates that in the cathode sheath, regardless of the bias, the argon ion is always dominant followed by $\mathrm{C}_{2} \mathrm{H}_{2}{ }^{+}$and then $\mathrm{NH}_{4}^{+}$. This phenomenon is consistent with the differences in the ion diffusivities, where $\mathrm{Ar}^{+}$has the lowest, $\mathrm{NH}_{4}{ }^{+}$has the highest, and $\mathrm{C}_{2} \mathrm{H}_{2}{ }^{+}$is in between, which results in differing rates of recombination at the cathode. The $\mathrm{NH}_{4}$ ion is displayed here because it is the most dominant nitrogen-bearing ion given the rapid charge exchange reaction $\mathrm{NH}_{3}{ }^{+}+\mathrm{NH}_{3} \rightarrow \mathrm{NH}_{4}^{+}+\mathrm{NH}_{2}\left(2.1 \times 10^{-9} \mathrm{~cm}^{3} / \mathrm{sec}\right){ }^{63}$ Figure 3(a) also 
shows that at the lowest bias of $325 \mathrm{~V}$ the dominant ion in the plasma bulk is the $\mathrm{NH}_{4}$ ion followed by $\mathrm{C}_{2} \mathrm{H}_{2}^{+}$and $\mathrm{Ar}^{+}$. The dissociation of $\mathrm{NH}_{3}$ at $750 \mathrm{~V}$ is higher than at $325 \mathrm{~V}$ and thus the $\mathrm{NH}_{4}^{+}$density decreases, and $\mathrm{Ar}^{+}$and $\mathrm{C}_{2} \mathrm{H}_{2}{ }^{+}$become the dominant ions in the bulk. The difference in dominance in the bulk and sheath at $325 \mathrm{~V}$ has to do with asymmetric charge exchange reactions given in Table I in which argon and hydrocarbon ions react with $\mathrm{NH}_{3}$ to produce ammonium ions without a reverse mechanism. This effect is not noticeable at the highest bias because of the reduced ammonia density.

In Fig. 3(b), the density of an incoming gas like $\mathrm{C}_{2} \mathrm{H}_{2}$ decreases with an increase in dc bias as more of the feedstock dissociates. Atomic hydrogen product goes up following increased dissociation of feedstock as the bias is increased. Not surprisingly, the general trend is that the feedstock concentrations decrease and dissociated product concentrations increase when the applied dc bias increases. Interestingly, Chhowalla et al. ${ }^{19}$ observed that the actual deposition rate decreases with an increase in dc bias, possibly due to greater etching by the dissociation product, atomic hydrogen.

Figure 4 displays the effect of bias on the gas temperature. At the lowest bias, the gas is mainly heated by gas-phase endothermic reactions that follow from the radicals that form from electron-impact reactions. At the highest bias, as show in Fig. 3(a), the plasma density is three orders of magnitude larger than at the lowest bias. Thus, ohmic heating from elastic collisions between neutrals and electrons becomes important as represented by the local maximum in the temperature profile near the cathode. 


\section{B. Filament Effects}

Next, we examine the effects of the filament on the system characteristics. Figure 5 displays the effect of changing the filament current on the gas temperature at $325 \mathrm{~V}$. The gas temperature is lower up to almost $2 \mathrm{~A}$ of current than for $0 \mathrm{~A}$, but at $2 \mathrm{~A}$ and above, the gas temperature indeed goes up due to filament heating. It is important to recognize that the filament does not always heat the gas, given the multiple sources of heating (substrate heater, plasma heating) and the level of filament current itself. Included in the figure is one carburization case at $15 \mathrm{~A}$. The effect is as expected; for the same current, carburization produces a higher filament temperature resulting from the higher resistivity and poisoning of the filament. The higher resistivity increases the power to the filament, and the poisoning reduces the energy lost through $\mathrm{H}_{2}$ atomization. The increased emissivity due to carburization does increase the amount of heat radiated but not enough to counter the increased resistivity or poisoning. Figure 6 shows the effect of the filament current on the densities of $\mathrm{C}_{2} \mathrm{H}_{2}$ and $\mathrm{C}_{2} \mathrm{H}_{4}$ along with atomic hydrogen; other species are not shown for the sake of clarity. Whether clean or carburized, the filament has no effect on any of the carbon-bearing species at the cathode where the sample for nanotube growth resides. The only effect it has at the location of interest is to increase the level of atomic hydrogen, at most by a factor of two.

Figure 7 shows the electron density and gas temperature as a function of filament current at $750 \mathrm{~V} \mathrm{dc}$ bias. At $15 \mathrm{~A}$, the gas temperature in the bulk plasma is lower than that for zero current. This is because the gas actually heats the filament under these conditions. Here, the heating resulting from the intense plasma is larger than that of the filament. The 
electron density simply is not affected by the filament current. This was also the case at the lower bias although not shown.

Figure 8 shows the effect of the filament on the neutral densities at $725 \mathrm{~V}$. The figure shows an interesting result when contrasted with Fig. 6. At the highest bias, the filament has little effect on any neutral species including atomic hydrogen. This can be explained by re-examining Figs. (5) and (7). At $325 \mathrm{~V}$, the gas temperature resulting from filament heating is larger than the non-filament case everywhere in the reactor chamber. This is not the case for the $750 \mathrm{~V}$ bias where the gas temperature is only affected by the filament in the region of the filament. This is likely due to the role of ohmic heating near the cathode which is not affected by the filament and is substantially larger than the filament heating in the cathode region. Since there are no observed differences in atomic hydrogen density with filament current at $750 \mathrm{~V}$, this suggests that the actual catalytic activity of the filament is not important in directly determining the cathode atomic hydrogen concentration except through its effect on the gas temperature. As stated previously, even in the case without significant ohmic heating at $325 \mathrm{~V}$ where the filament does affect the gas temperature near the substrate, there is little effect on the species of relevance to carbon nanotube growth. This perhaps explains the observation by Han et al. ${ }^{62}$ that the plasma intensity plays a more important role than the filament current in CNT growth and that well-aligned nanotubes can be grown without filament current. Hayashi $e t$ al ${ }^{64}$ also arrived at similar conclusions since they were able to grow well-aligned nanotubes on the entire substrate uniformly with a dc bias instead of just in the small area under the filament. 


\section{CONCLUDING REMARKS}

Plasma enhanced CVD has emerged as a means to grow vertically aligned MWNTs and MWNFs. DC plasmas have been reported in the literature both with and without the aid of a hot filament. Here we have developed a model to analyze the plasma physics and chemistry as well as filament effects. One-dimensional simulations of an acetylene/ammonia system have been performed. The dc bias on the substrate plays an important role as it controls the sheath electric field affecting CNT orientation, extent of dissociation, and production of neutral species. Unlike CVD growth systems without plasma enhancement, the filament does not appear to have any significant effect if other mechanisms of regulating the substrate growth temperature are employed. We are currently working on adding surface chemistry, though rudimentary, and with this, additional parametric studies and $2 \mathrm{D}$ effects can be investigated.

\section{ACKNOWLEDGMENTS}

Work by DB was supported under NASA contract NAS2-99092 to Eloret Corporation. Authors acknowledge valuable discussions on dc-HFCVD experiments with Alan Cassell, Laura Ye, and Brett Cruden. 


\section{References}

1. Y. Chen, Z. L. Wang, J. S. Yin, D. J. Johnson, and R. H. Prince, Chem. Phys. Lett. 272, 178 (1997).

2. Y. Chen, L. P. Guo, D. J. Johnson, and R. H. Prince, J. Cryst. Growth 193, 342 (1998).

3. L.C. Qin, D. Zhou, A. R. Krauss, and D. M. Gruen, Appl. Phys. Lett. 72, 3437 (1998).

4. Z. F. Ren, Z. P. Huang, J. W. Xu, J. H. Wang, P. Bush, M. P. Siegel, and P. N. Provencio, Science 282, 1105 (1998).

5. S. H. Tsai, C. W. Chao, C. L. Lee, and H. C. Shin, Appl. Phys. Lett. 74, 3462 (1999).

6. Q. Zhang, S. F. Yoon, J. Ahn, B. Gan, Rusli, and M.-B. Yu, J. Phys. Chem. Solids 61, $1179(2000)$

7. Y. C. Choi, Y. H. Lee, B. S. Lee, G. Park, W. B. Choi, N. S. Lee, and J. M. Kim, J. Vac. Sci. Technol. A 18, 1864 (2000).

8. Y. C. Choi, Y. M. Shin, S. C. Lim, D. J. Bae, Y. H. Lee, B. S. Lee, and D. Chung, J. Appl. Phys. 88, 4898 (2000). 
9. M. Okai, T. Muneyoshi, T. Yaguchi, and S. Sasaki, Appl. Phys. Lett. 77, 3465 (2000).

10. C. Bower, W. Zhu, S. Jin, and O. Zhou, Appl. Phys. Lett. 77, 830 (2000).

11. C. Bower, O. Zhou, W. Zhu, D. J. Werder, and S. Jin, Appl. Phys. Lett. 77, 2767 (2000).

12. H. Cui, O. Zhou, and B. R. Stoner, J. Appl. Phys. 88, 6072 (2000).

13. V. I. Merkulov, D. H. Lowndes, Y. Y. Wei, G. Eres, and E. Voelkl, Appl. Phys. Lett. 76, 3555 (2000).

14. Y. Y. Wei, G. Eres, V. I. Merkulov, and D. H. Lowndes, Appl. Phys. Lett. 78, 1394 (2001).

15. V. I. Merkulov, M. A. Guillorn, D. H. Lowndes, M. L. Simpson, and E. Voelkl, Appl. Phys. Lett. 79, 1178 (2001).

16. V. I. Merkulov, A. V. Melechko, M. A. Guillom, D. H. Lowndes, and M. L. Simpson, Appl. Phys. Lett. 79, 2970 (2001).

17. G. W. Ho, A. T. S. Wee, J. Lin, and W. C. Tjiu, Thin Solid Films 388, 73 (2001).

18. K. B. K. Teo, M. Chhowalla, G. A. J. Amaratunga, W. I. Milne, D. G. Hasko, G. Pirio, P. Legagneux, F. Wyczisk, and D. Pribat, Appl. Phys. Lett. 79, 1534 (2001). 
19. M. Chhowalla, K. B. K. Teo, C. Ducati, N. L. Rupersinghe, G. A. J. Amaratunga, A. C. Ferrari, D. Roy, J. Robertson, and W. I. Milne, J. Appl. Phys. 90, 5308 (2001).

20. K. B. K. Teo, M. Chhowalla, G. A. J. Amaratunga, W. I. Milne, G. Pirio, P. Legagneux, F. Wyczisk, J. Olivier, and D. Pribat, J. Vac. Sci. Technol. B 20, 116 (2002).

21. M. Tanemura, K. Iwata, K. Takahashi, Y. Fujimoto, F. Okuyama, H. Sugie, and V. Filip, J. Appl. Phys. 90, 1529 (2001).

22. C. L. Tsai, C. F. Chen, and L. K. Wu, Appl. Phys. Lett. 81, 721 (2002).

23. L. Delzeit, I. McAninch, B. A. Cruden, D. Hash, B. Chen, J. Han, and M. Meyyappan, J. Appl. Phys. 91, 6027 (2002).

24. L. Delzeit, C. V. Nguyen, R. M. Stevens, J. Han, and M. Meyyappan, Nanotechnology 13, 280 (2002).

25. K. Matthews, B. Cruden, B. Chen, M. Meyyappan, and L. Delzeit, J. Nanosci. Nanotech. 2, 475 (2002).

26. O.M. Kuttel, O. Groening, C. Emmenbegger, and L. Schlapbach, Appl. Phys. Lett. 73, 2113 (1998).

27. J. Han, W. S. Yang, J. B. Yoo, and C. Y. Park, J. Appl. Phys. 88, 7363 (2000). 
28. J. Han, J. B. Yoo, C. Y. Park, H. J. Kim, G. S. Park, M. Yang, I. T. Han, N. Lee, W. Yi, S. G. Yu, and J. M. Kim, J. Appl. Phys. 91, 483 (2002).

29. D. Nolan, D. C. Lynch, and A. H. Cutler, J. Phys. Chem. B 102, 4165 (1998).

30. D. Hash and M. Meyyappan, J. Appl. Phys. 92, in press (2003).

31. C. Dateo, T. Gökçen, and M. Meyyappan, J. Nanosci. Nanotech. 2, 523 (2002).

32. T. Gökçen, C. Dateo, and M. Meyyappan, J. Nanosci. Nanotech. 2, 535 (2002).

33. S. J. Harris, A. W. Weiner, and T. A. Perry, Appl. Phys. Lett. 53, 1605 (1988).

34. M. Frenklach, J. Appl. Phys. 65, 5142 (1989).

35. T. DebRoy, K. Tankala, W. A. Yarbrough, and R. Messier, J. Appl. Phys. 68, 2424 (1990).

36. D. G. Goodwin and G. G. Gavillet, J. Appl. Phys. 68, 6393 (1990).

37. M. Frenklach and H. Wang, Phys. Rev: B 43, 1520 (1991).

38. D. S. Dandy and M. E. Coltrin, J. Appl. Phys. 76, 3102 (1994).

39. M. C. McMaster, W. L. Hsu, M. E. Coltrin, and D. S. Dandy, J. Appl. Phys. 76, 7567 (1994).

40. L. L. Connell, J. W. Fleming, H.-N. Chu, D. J. Vestyck, E. Jensen, and J. E. Butler, J. Appl. Phys. 78, 3622 (1995). 
41. B. Ruf, F. Behrendt, O. Deutschmann, and J. Warnatz, J. Appl. Phys. 79, 7256 (1996).

42. Y. A. Mankelevich, A. T. Rakhimov, and N. V. Suetin, Diamond Relat. Mater. 5, 888 (1996)

43. Y. A. Mankelevich, A. T. Rakhimov, and N. V. Suetin, Diamond Relat. Mater. 7, 1133 (1998).

44. Y. A. Mankelevich, N. V. Suetin, M. N. R. Ashfold, J. A. Smith, and E. Cameron, Diamond Relat. Mater. 10, 364 (2001).

45. Y. A. Mankelevich, N. V. Suetin, , J. A. Smith, and M. N. R. Ashfold, Diamond Relat. Mater. 11, 567 (2002).

46. J. A. Smith, J. B. Wills, H. S. Moores, A. J. Orr-Ewing, and M. N. R. Ashfold, J. Appl. Phys. 92, 672 (2002).

47. CRC Handbook of Chemistry and Physics, $83^{\text {rd }}$ ed. edited by D. R. Lide (CRC Press, Boca Raton, FL, 2002).

48. T. Durakiewicz and S. Halas, J. Vac. Sci. Technol. A 16, 194 (1998).

49. E. Zeiler, S. Schwarz, S. M. Rosiwal, and R. F. Singer, Mater. Sci. Eng. A335, $236(2002)$. 
50. H. F. Winters, H. Seki, R. R. Rye, and M. E. Coltrin, J. Appl. Phys. 76, 1228 (1994).

51. E. Lassner and W.-D. Schubert, Tungsten (Kluwer Academic, New York, 1999).

52. Thermophsyical Properties of High Temperature Solid Materials, edited by Y. S. Touloukian (Macmillan, New York, 1967).

53. J. R. Welty, C. E. Wicks, and R. E. Wilson, Fundamentals of Momentum, Heat, and Mass Transfer (Wiley, New York, 1969).

54. L. Stobiński and R. Duś, Vacuum 46, 433 (1995).

55. Yu. P. Raizer, Gas Discharge Physics (Springer, Berlin, 1997).

56. P. M. Chung, Phys. Fluids 12, 1623 (1969).

57. D. B. Graves and K. F. Jensen, IEEE Trans. Plasma Sci. PS-14, 78 (1986).

58. D. Bose, T. R. Govindan, and M. Meyyappan, J. Electrochem. Soc. 146, 2705 (1999).

59. D. Bose, T. R. Govindan, and M. Meyyappan, IEEE Trans. Plasma Sci. 30, 653 (2002)

60. M. Meyyappan and J. P. Kreskovsky, J. Appl. Phys. 68, 1506 (1990).

61. The reaction set can be obtained by sending a request to David.B.Hash@nasa.gov. 
62. J. H. Han, C. H. Lee, D. Y. Jung, C. W. Yang, J. B. Yoo, C. Y. Park, H. J. Kim, S. G. Yu, W. Yi, G. S. Park, I. T. Han, N. S. Lee, and J. M. Kim, Thin Solid Films 409, 120 (2002).

63. V. G. Anicich, J. Phys. Chem. Ref. Data 22, 1469 (1993).

64. Hayashi, T. Negishi, and S. Nishino, J. Vac. Sci. Technol. A 19, 1796 (2001).

65. V. G. Anicich and M. J. McEwan, Planet. Space Sci. 45, 897 (1997).

66. M. Tsuji, H. Kouno, K. Matsumura, T. Funatsu, Y. Nishimura, H. Obase, H. Kugishima, and K. Yoshida, J. Chem. Phys. 98, 2011 (1993). 
Table I. Asymmetric charge exchange reactions

\begin{tabular}{|c|c|c|}
\hline Reaction & Rate $\left(\mathrm{cm}^{3} / \mathrm{sec}\right)$ & Reference \\
\hline $\mathrm{C}_{2} \mathrm{H}_{2}^{+}+\mathrm{H}_{2} \rightarrow \mathrm{C}_{2} \mathrm{H}_{3}^{+}+\mathrm{H}$ & $1.0 \times 10^{-11}$ & Anicich $^{63}(1993)$ \\
\hline $\mathrm{C}_{2} \mathrm{H}_{2}^{+}+\mathrm{NH}_{3} \rightarrow \mathrm{NH}_{3}^{+}+\mathrm{C}_{2} \mathrm{H}_{2}$ & $2.14 \times 10^{-9}$ & Anicich $^{63}(1993)$ \\
\hline $\mathrm{C}_{2} \mathrm{H}_{2}^{+}+\mathrm{NH}_{3} \rightarrow \mathrm{NH}_{4}^{+}+\mathrm{C}_{2} \mathrm{H}$ & $9.61 \times 10^{-10}$ & Anicich $^{63}(1993)$ \\
\hline $\mathrm{C}_{2} \mathrm{H}_{3}^{+}+\mathrm{H} \rightarrow \mathrm{C}_{2} \mathrm{H}_{2}^{+}+\mathrm{H}_{2}$ & $6.8 \times 10^{-11}$ & Anicich and McEwan ${ }^{65}$ (1997) \\
\hline $\mathrm{C}_{2} \mathrm{H}_{3}^{+}+\mathrm{NH}_{3} \rightarrow \mathrm{NH}_{4}^{+}+\mathrm{C}_{2} \mathrm{H}_{2}$ & $2.48 \times 10^{-9}$ & Anicich $^{63}(1993)$ \\
\hline $\mathrm{NH}_{3}^{+}+\mathrm{H}_{2} \rightarrow \mathrm{NH}_{4}^{+}+\mathrm{H}$ & $4.4 \times 10^{-13}$ & Anicich $^{63}$ (1993) \\
\hline $\mathrm{NH}_{3}^{+}+\mathrm{C}_{2} \mathrm{H}_{4} \rightarrow \mathrm{NH}_{4}^{+}+\mathrm{C}_{2} \mathrm{H}_{3}$ & $1.4 \times 10^{-9}$ & Anicich $^{63}$ (1993) \\
\hline $\mathrm{NH}_{3}^{+}+\mathrm{NH}_{3} \rightarrow \mathrm{NH}_{4}^{+}+\mathrm{NH}_{2}$ & $2.1 \times 10^{-9}$ & Anicich $^{63}$ (1993) \\
\hline $\mathrm{Ar}^{+}+\mathrm{C}_{2} \mathrm{H}_{2} \rightarrow \mathrm{C}_{2} \mathrm{H}_{2}^{+}+\mathrm{Ar}$ & $4.2 \times 10^{-10}$ & Tsuji et al. ${ }^{66}(1993)$ \\
\hline $\mathrm{Ar}^{+}+\mathrm{C}_{2} \mathrm{H}_{4} \rightarrow \mathrm{C}_{2} \mathrm{H}_{2}^{+}+\mathrm{H}_{2}+\mathrm{Ar}$ & $2.2 \times 10^{-10}$ & Tsuji et al. ${ }^{66}(1993)$ \\
\hline $\mathrm{Ar}^{+}+\mathrm{C}_{2} \mathrm{H}_{4} \rightarrow \mathrm{C}_{2} \mathrm{H}_{3}^{+}+\mathrm{H}+\mathrm{Ar}$ & $8.35 \times 10^{-10}$ & Tsuji et al. ${ }^{66}(1993)$ \\
\hline $\mathrm{Ar}^{+}+\mathrm{NH}_{3} \rightarrow \mathrm{NH}_{3}^{+}+\mathrm{Ar}$ & $1.6 \times 10^{-9}$ & Anicich $^{63}$ (1993) \\
\hline
\end{tabular}




\section{Figure Captions}

1. Concentration of various neutral species at $-325 \mathrm{~V}$ cathode bias. Pressure of 8 Torr; substrate temperature of $700^{\circ} \mathrm{C}$; and $100 / 50 / 25 \mathrm{sccm}$ of $\mathrm{Ar} / \mathrm{C}_{2} \mathrm{H}_{2} / \mathrm{NH}_{3}$. No filament heating is used.

2. Effect of dc bias on (a) electron temperature and (b) electric field; conditions are as in Fig. 1.

3. Effect of dc bias on (a) ion densities and (b) neutral densities for the same conditions as in Fig. 1.

4. Effect of dc bias on gas temperature for the same conditions as in Fig. 1.

5. Effect of filament current on gas temperature at a de bias of $-325 \mathrm{~V}$.

6. Effect of filament current on neutral densities at a dc bias of $-325 \mathrm{~V}$.

7. Effect of filament current on electron density and gas temperature at a dc bias of $-750 \mathrm{~V}$.

8. Effect of filament current on neutral densities at a dc bias of $-750 \mathrm{~V}$. 


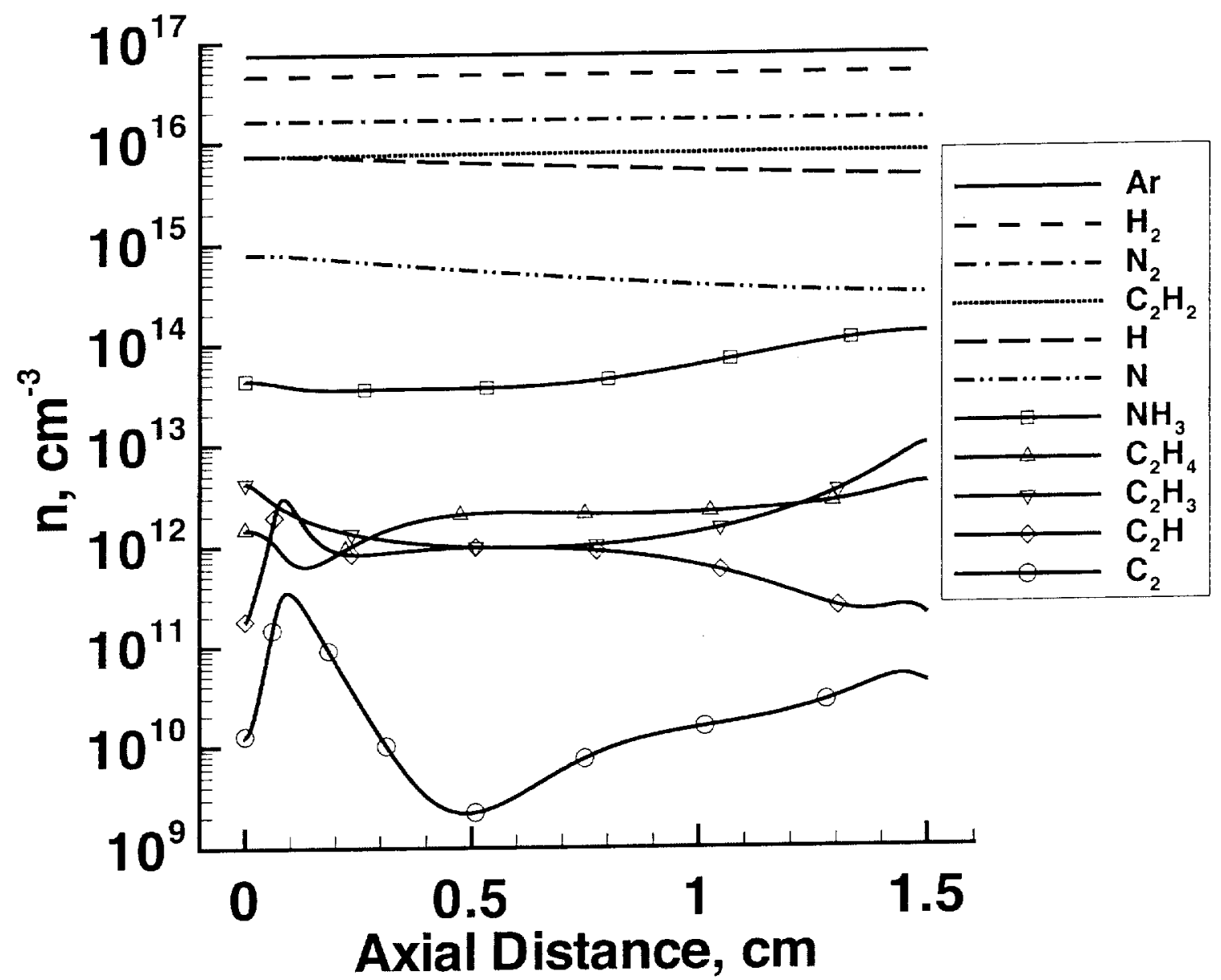

Fig. 1 


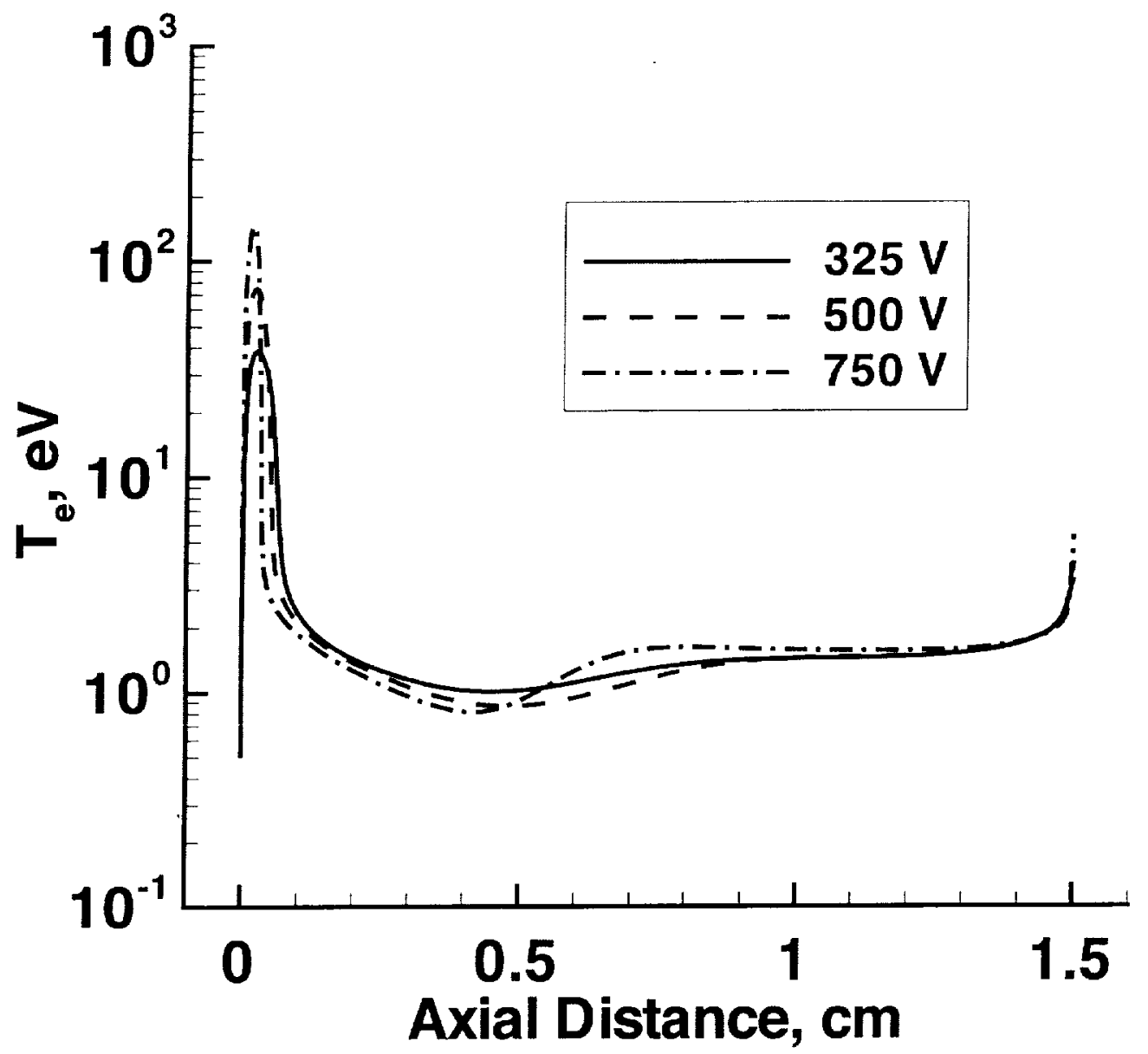

Fig. 2(a) 


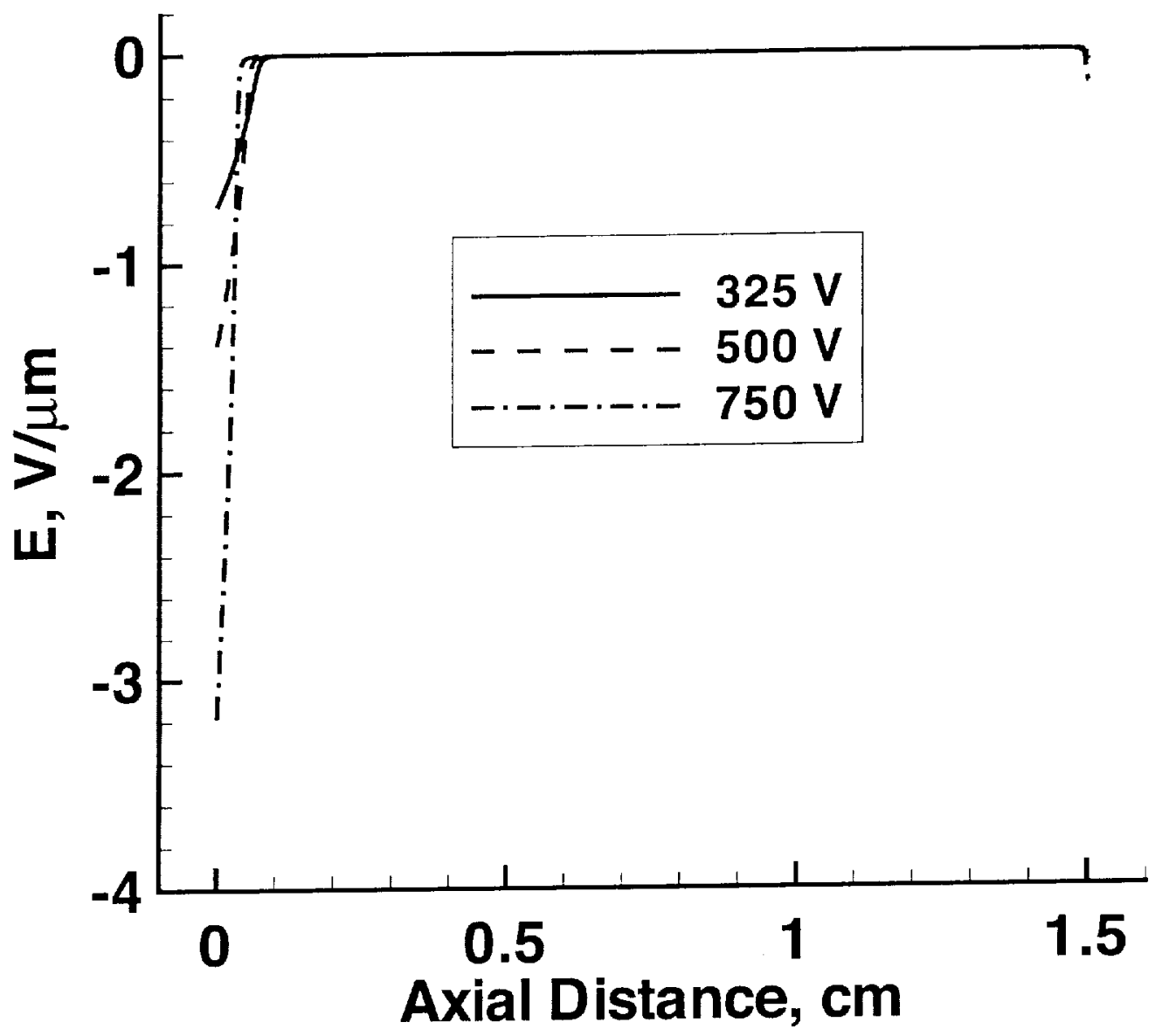

Fig. 2(b) 


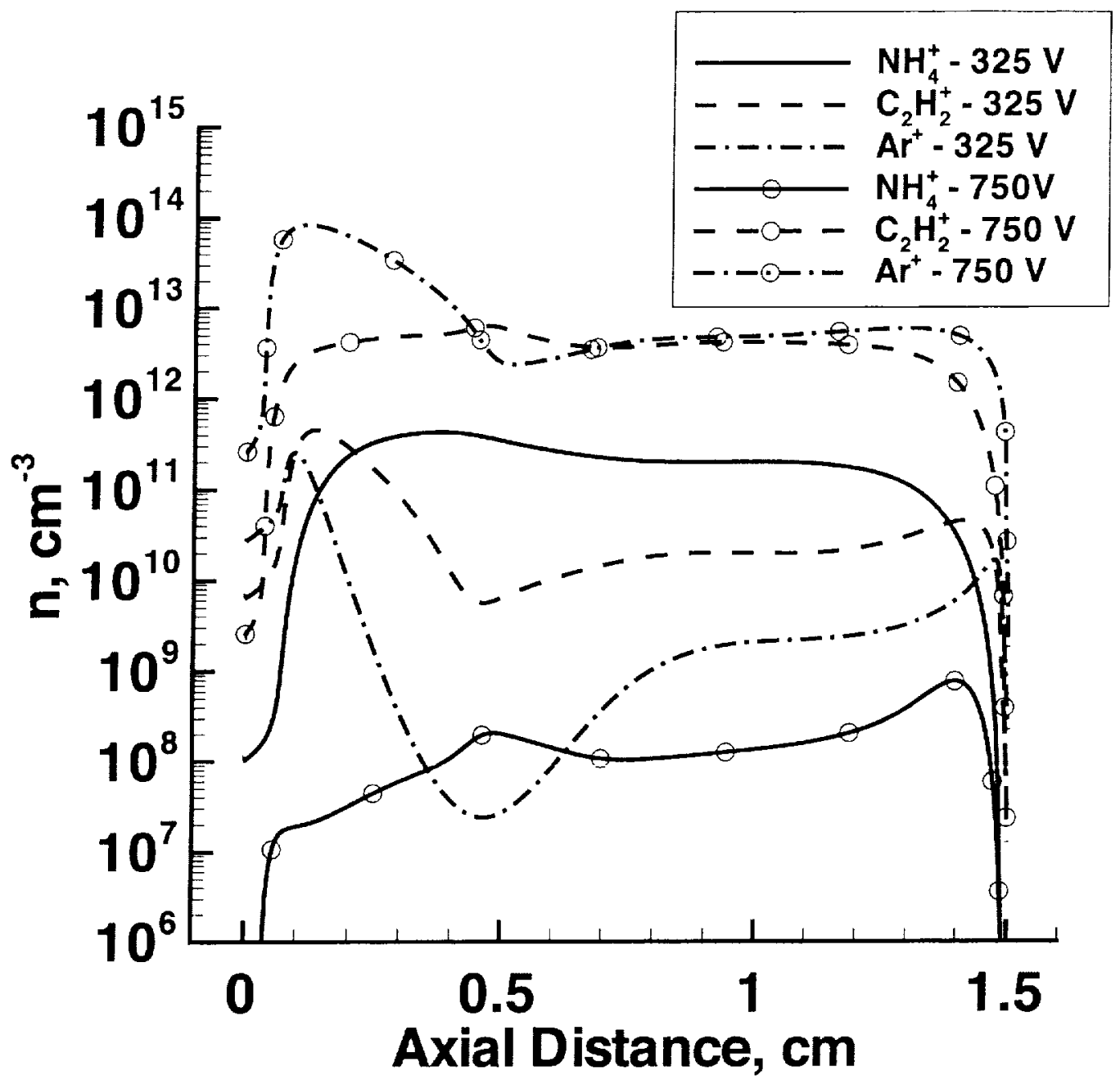

Fig. 3(a) 


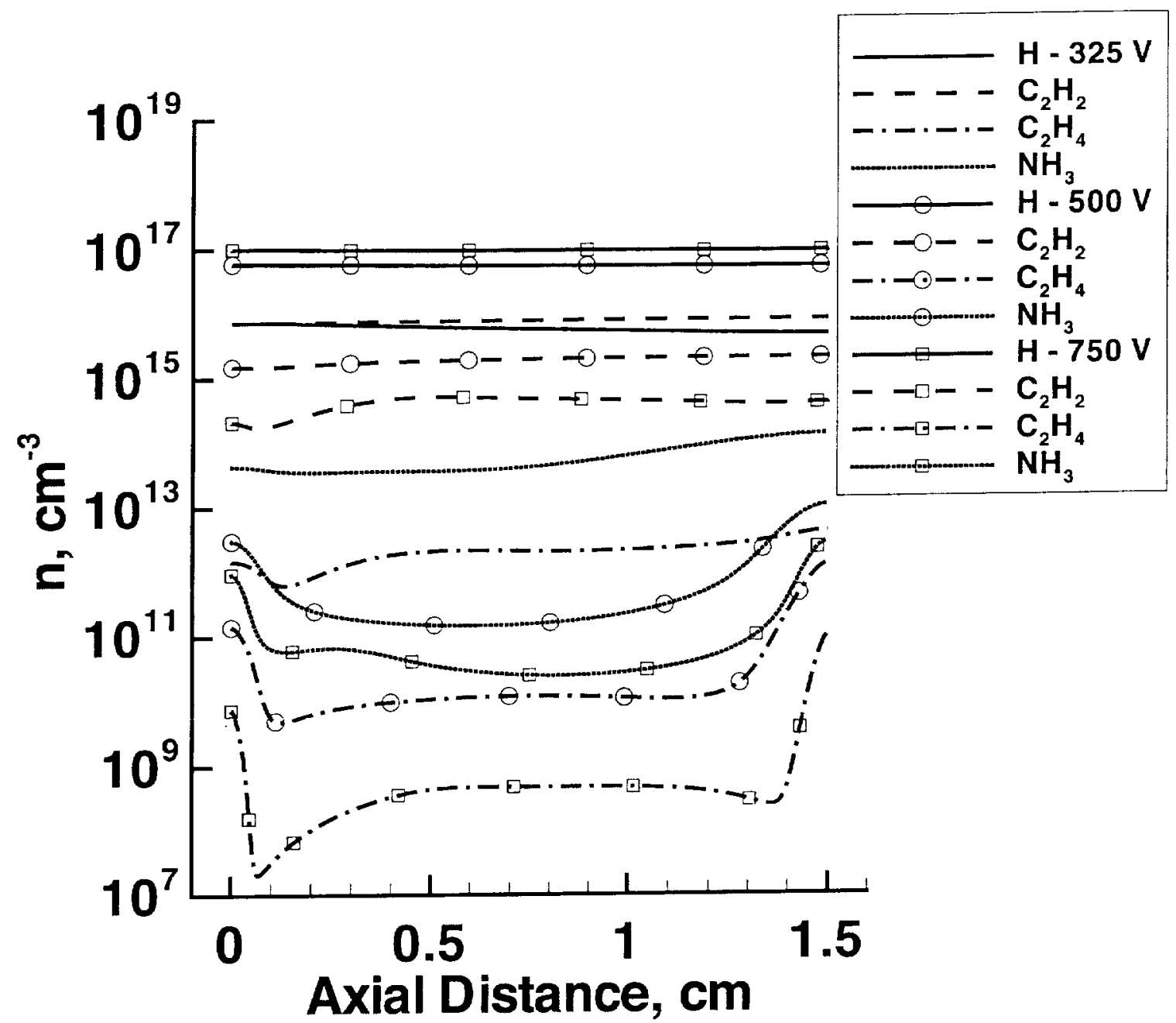

Fig. 3(b) 


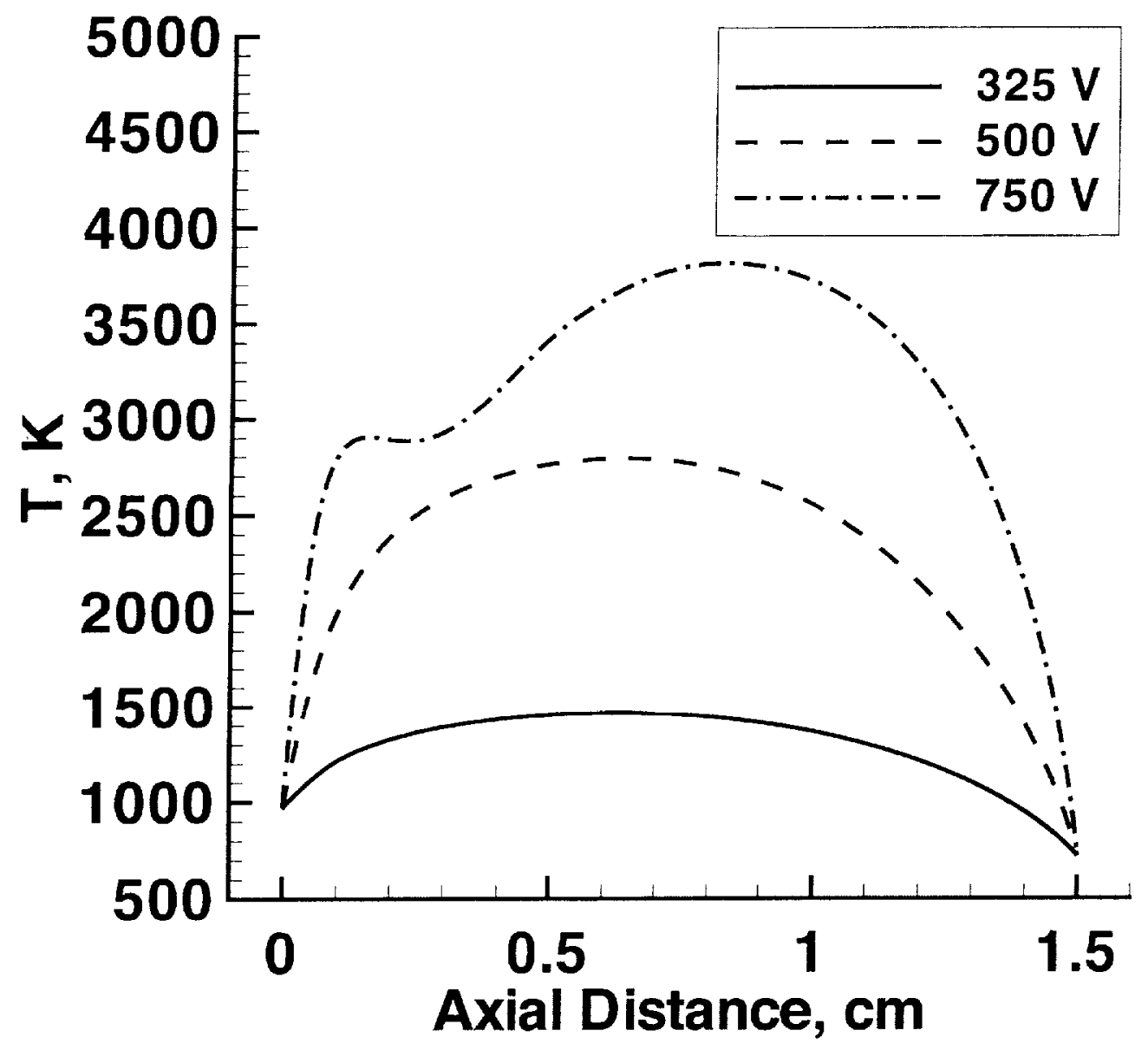

Fig. 4 


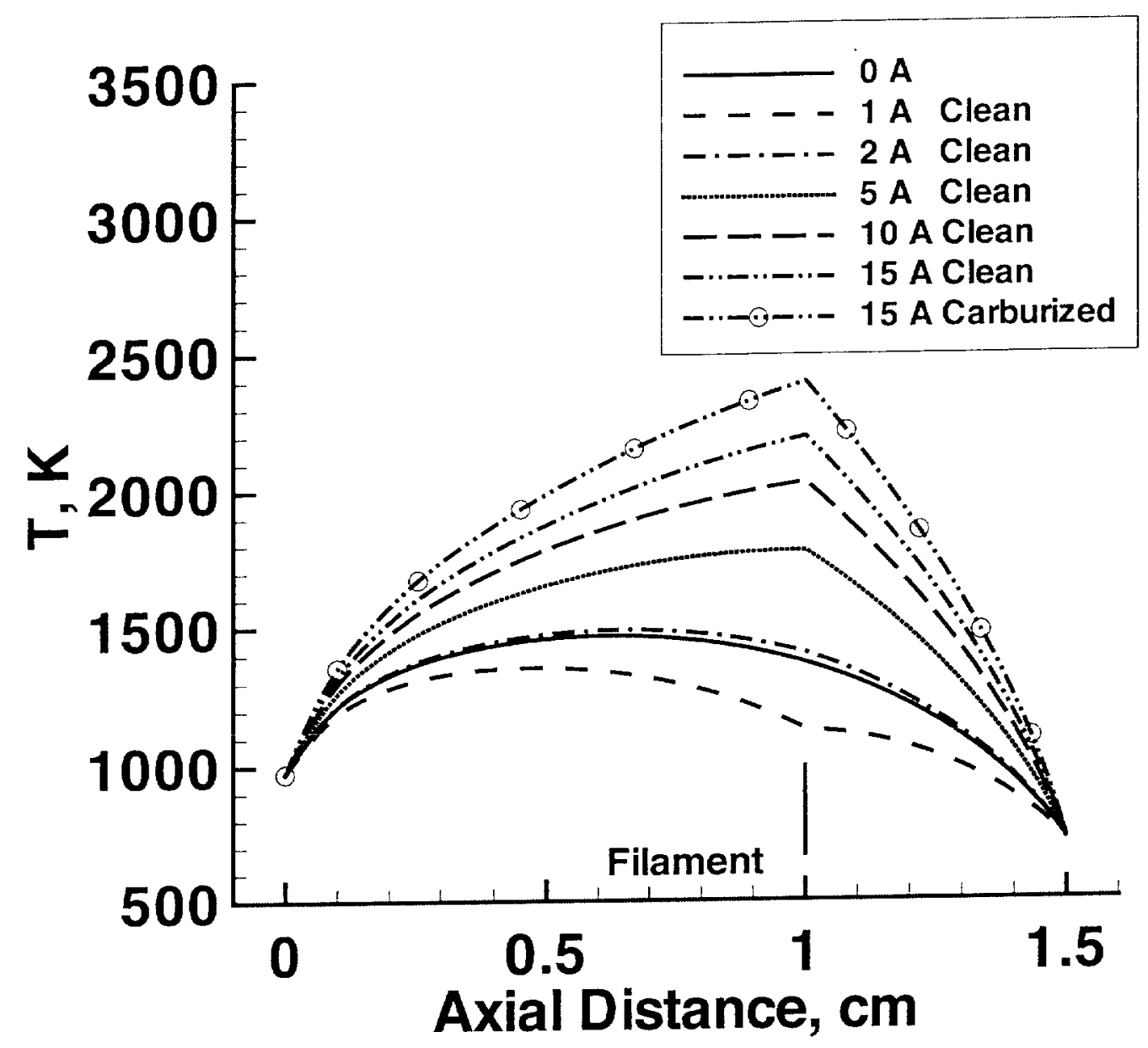

Fig. 5 


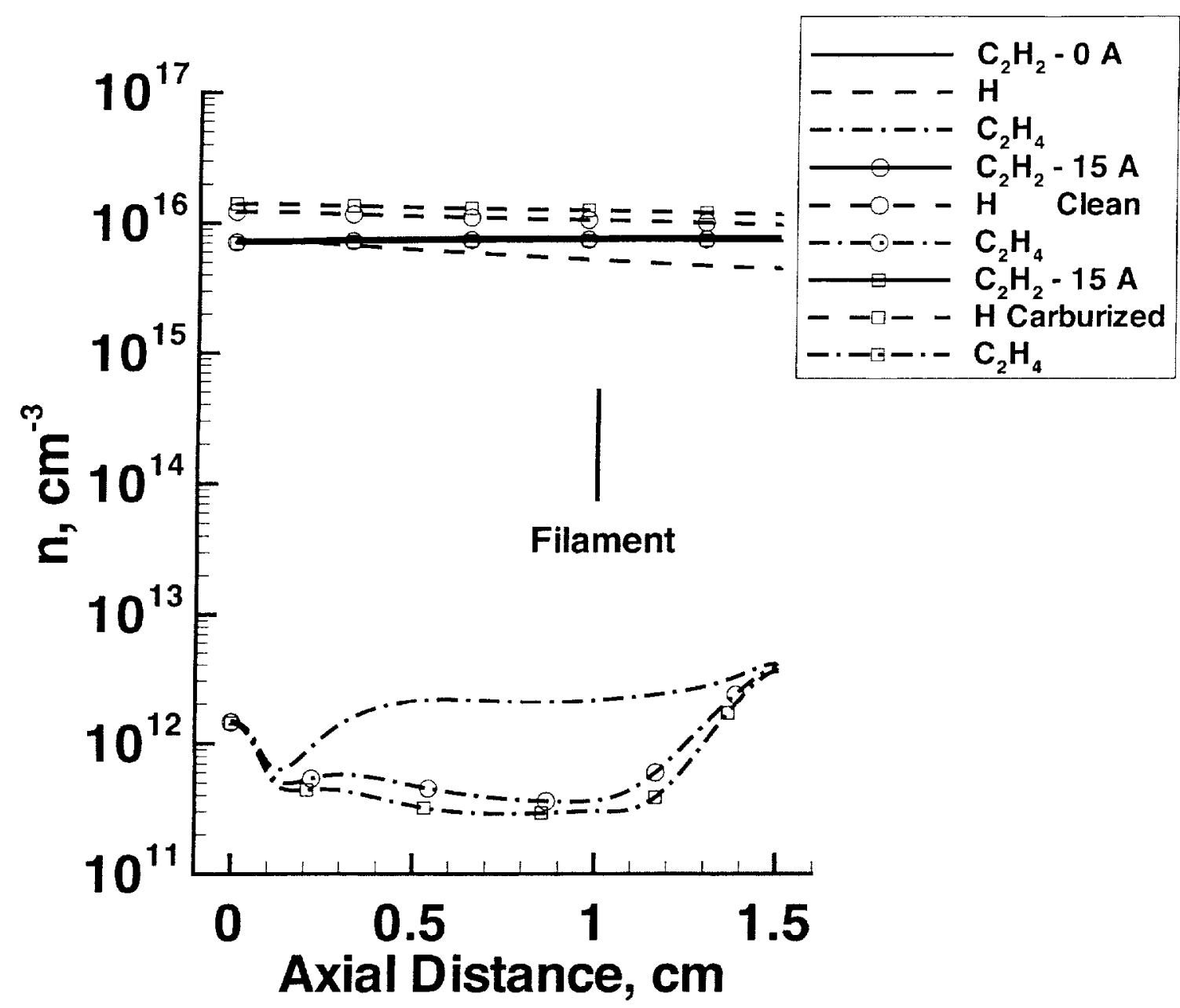

Fig. 6 


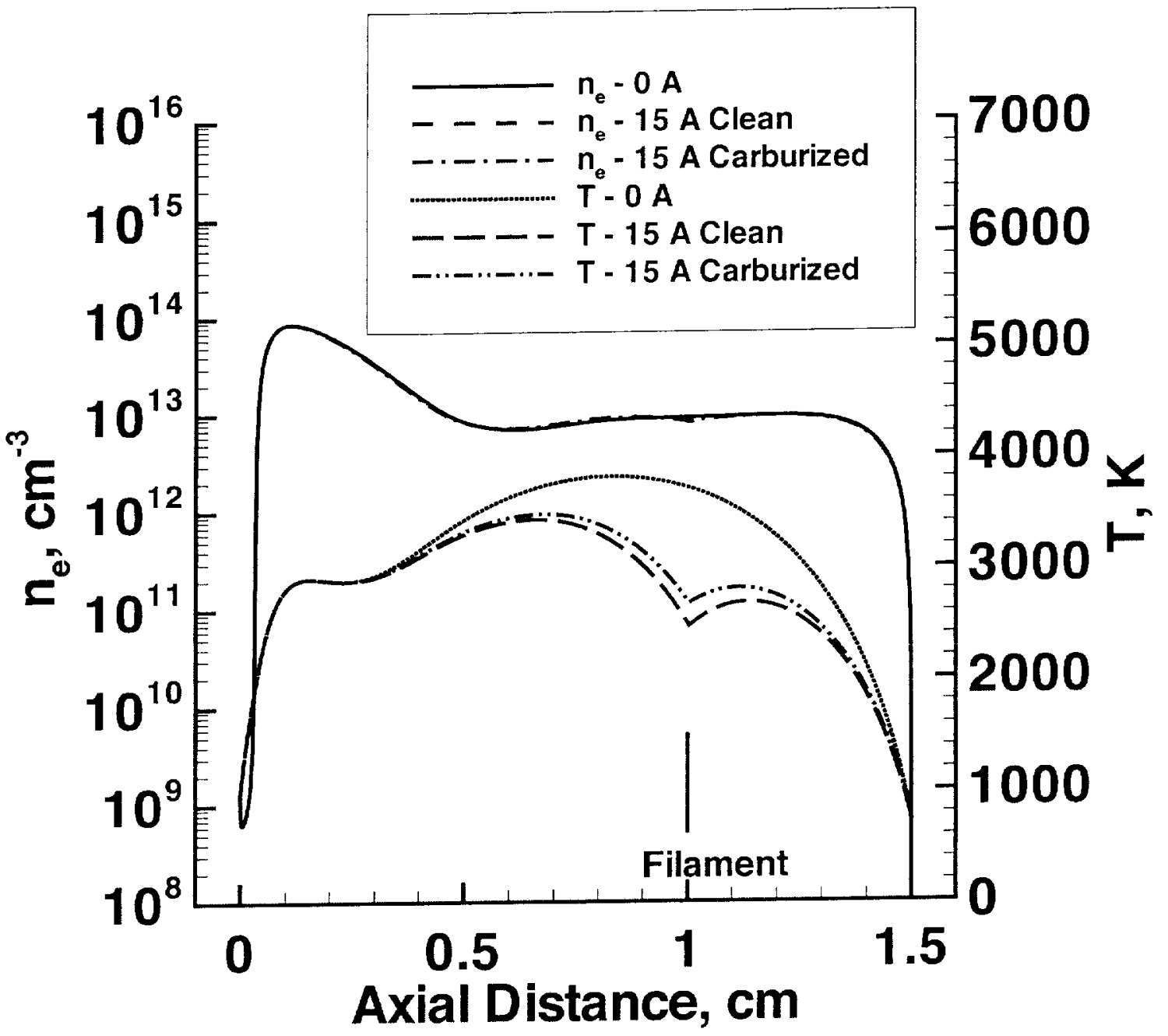

Fig. 7 


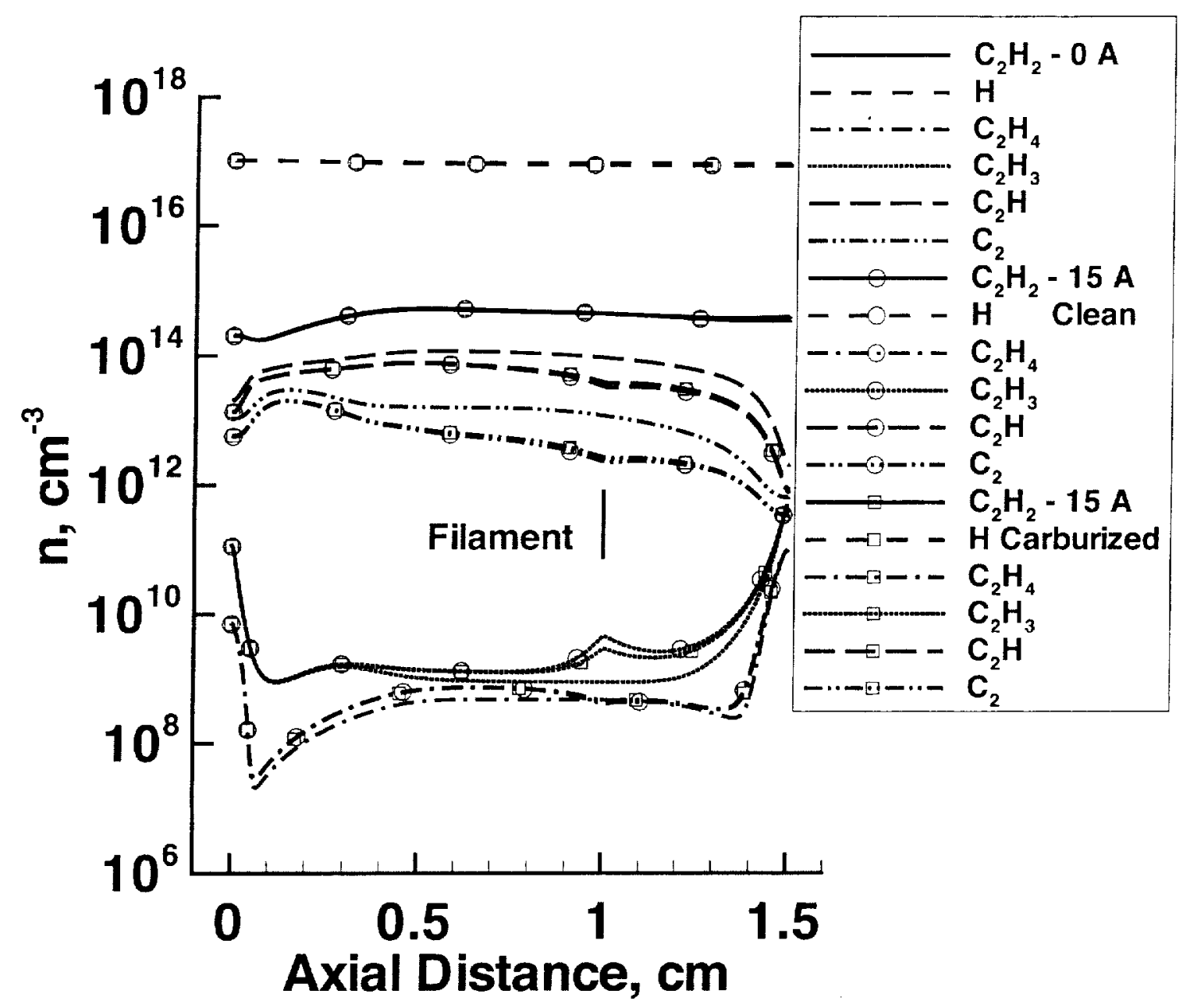

Fig. 8 